\title{
Carotid Near-Occlusion: A Comprehensive Review, Part 2_-Prognosis and Treatment, Pathophysiology, Confusions, and Areas for Improvement
}

E. Johansson and A.J. Fox

\section{ABSTRACT}

SUMMARY: In Part 1 of this review, the definition, terminology, and diagnosis of carotid near-occlusion were presented. Carotid nearocclusions (all types) showed a lower risk of stroke than other severe stenoses. However, emerging evidence suggests that the nearocclusion prognosis with full collapse (higher risk) differs from that without full collapse (lower risk). This systematic review presents what is known about carotid near-occlusion. In this second part, the foci are prognosis and treatment, pathophysiology, the current confusion about near-occlusion, and areas in need of future improvement.

ABBREVIATIONS: ARR = absolute risk reduction; $\mathrm{CCA}=$ common carotid artery; $\mathrm{ECA}=$ external carotid artery; $\mathrm{PCA}=$ posterior cerebral artery; $\mathrm{ECST}=\mathrm{E}$ European Carotid Surgery Trial

C arotid near-occlusion is distal luminal collapse of the internal carotid artery beyond a tight stenosis. ${ }^{1}$ Please refer to the first part of this review for the literature review, definition, terminology, and diagnosis of carotid near-occlusion. ${ }^{2}$ Near-occlusion without full collapse seems to be commonly overlooked by some researchers and clinicians. Emerging evidence suggests a difference in prognosis, depending on the degree of collapse. ${ }^{3}$

The aim of Parts 1 and 2 of this review was to present the definition, terminology, diagnosis, prognosis, treatment, and pathophysiology of carotid near-occlusion; and highlight areas of confusion and those in need of future improvement. In this second part, the foci are prognosis and treatment, pathophysiology, the current confusion about near-occlusion, and areas in need of improvement.

\section{Prognosis and Treatment}

The NASCET and European Carotid Surgery Trial (ECST) included 246 cases of near-occlusion without full collapse and 16 cases of near-occlusion with full collapse. ${ }^{1}$ The cases with full collapse were few, and none had recurrent stroke, so all cases of

From the Department of Pharmacology and Clinical Neuroscience (E.J.), Umeå University, Umeå, Sweden; and Department of Neuroradiology (A.J.F.), Sunnybrook Heath Sciences Centre, University of Toronto, Toronto, Ontario, Canada.

This work was funded by the Swedish Stroke Foundation, the Northern Swedish Stroke Fund, the foundation for neuroscientific research at Umeå University Hospital, the County of Västerbotten, and the Medical Faculty of Umeå University.

Please address correspondence to Elias Johansson, MD, Department of Neurology, Institution of Pharmacology and Clinical Neuroscience, Umeå University, 90182 Umeå, Sweden; e-mail: elias.johansson@umu.se

- Indicates open access to non-subscribers at www.ajnr.org

http://dx.doi.org/10.3174/ajnr.A4429 near-occlusion were analyzed together. For near-occlusions randomized to medical treatment or surgery, the 3-year risk of ipsilateral stroke was $15.1 \%$ and $10.9 \%$, respectively (absolute risk reduction $[\mathrm{ARR}$ ], $4.2 \% ; P=.33$ ). In cases with 70\%-99\% stenosis without near-occlusion randomized to medical treatment or surgery, the 3-year risk of ipsilateral stroke was $26.0 \%$ and $8.2 \%$, respectively (ARR, $17.8 \% ; P<.001$ ). ${ }^{1}$ The risk of perioperative stroke and death was similar for near-occlusion $(5.4 \% ; 8 / 148)$ and $70 \%-99 \%$ stenosis $(6.2 \% ; 36 / 581),{ }^{4}$ and slightly lower periprocedural risks have been reported since then. ${ }^{5}$ Because $94 \%$ of nearocclusions were without full collapse, the findings from NASCET and ECST are mostly applicable to this group of near-occlusions. ${ }^{1}$ However, there was no indication that near-occlusion with full collapse differed. ${ }^{1}$

In 1983, Ringelstein et $\mathrm{al}^{6}$ concluded that "immediate diagnostic clarification and emergency endarterectomy are mandatory" for near-occlusion with full collapse, diagnosed with low-flow findings on continuous-wave Doppler. However, this opinion was not an observed high risk of recurrent stroke but was based on that of 9 patients: Two had crescendo TIA at baseline, 2 had crescendo amaurosis fugax at baseline, and 2 rapidly progressed to occlusion. In fact, no risk of recurrent stroke was reported. ${ }^{6}$ In 1989, O'Leary et $\mathrm{al}^{7}$ reported that of 9 patients with near-occlusion (most likely with full collapse) who did not undergo carotid endarterectomy, 2 had an angiographic stroke and 3 had a recurrent ipsilateral stroke within 1 year. Presumably, the angiographic strokes affected further management. Recently, in a small study of 10 cases with near-occlusion with full collapse, 4 (40\%) had an ipsilateral ischemic stroke within 1 month of presentation, 
whereas none of 15 patients with near-occlusion without full collapse had recurrent stroke $(P=.023) .^{3}$

Even if near-occlusion with full collapse might show a high risk of recurrent stroke, the evidence level is poor. Indeed, because only approximately half ( $n \approx 8$ ) of the near-occlusions with full collapse were observed without an operation in NASCET and ECST, and Ringelstein et $\mathrm{al}^{6}$ did not report the risk of recurrent stroke, the risk of recurrent stroke without or before carotid endarterectomy has only been reported for approximately 27 patients. $^{1,3,7}$ Of these, $26 \%(7 / 27 ; 95 \% \mathrm{CI}, 8 \%-44 \%)$ had a recurrent stroke within 1 year-ie, roughly equal to the 3 -year risk of $70 \%-99 \%$ stenoses (but with a wide margin of error). If anything, $26 \%$ might be an underestimation because some were not followed for a full year and some were not followed from the presenting event. This high risk was not observed in NASCET and ECST, possibly because of the long delay between the last event and the study entry (an overall delay of $>4$ weeks in $>50 \%$ of cases), ${ }^{1}$ whereas a recent study found that all recurrent strokes occurred within 4 weeks. ${ }^{3}$

Asymptomatic near-occlusion prognosis has not been studied. Some near-occlusion cases without full collapse were likely, but unintentionally, included in the Asymptomatic Carotid Surgery Trial. ${ }^{8}$ In this trial, the diagnosis of carotid stenosis was mostly made with sonography, which cannot distinguish carotid stenosis and near-occlusion without full collapse. Because near-occlusions were not identified, they were not separately analyzed.

\section{Pathophysiology}

Nature of Near-Occlusion. A few studies shed light on the nature of near-occlusion:

- Conventional stenoses can progress to near-occlusion. ${ }^{1}$

- Intraoperative back pressure is higher in cases of near-occlusion with full collapse (mean, $56 \pm 15 \mathrm{~mm} \mathrm{Hg}$ ) than for those with conventional stenosis (mean, $33 \pm 13 \mathrm{~mm} \mathrm{Hg}$ ). ${ }^{9}$

- Flow velocities are high in near-occlusion without full collapse and can be high or low in near-occlusion with full collapse., ${ }^{3,10-12}$

- Collaterals reaching the ipsilateral MCA via the anterior communicating artery, posterior communicating artery, and/or the ophthalmic artery on conventional angiography are present in $64 \%, 43 \%, 25 \%$, and $<5 \%$ in cases with near-occlusion (with and without full collapse), with $85 \%-99 \%$ stenosis, $70 \%-84 \%$ stenosis, and $<70 \%$ stenosis respectively. ${ }^{13}$ Any flow in intracranial collaterals has been reported in $96 \%$ of cases with nearocclusion (with and without full collapse). ${ }^{14}$

- Both CBF and SPECT blood flow reactions to acetazolamide are lower among patients with near-occlusion (likely with full collapse alone) than in both patients with 70\%-99\% stenoses and disease-free controls. ${ }^{15}$ Before carotid stenting, 20\% (3/15) of those with near-occlusions had $>10 \%$ blood flow increase with acetazolamide; after carotid stenting, 100\% (15/15) had $>10 \%$ increase. ${ }^{15}$ Some studies included measurements of intracerebral hemodynamics, without analyzing them in detail. ${ }^{16-19}$

- Near-occlusion with full collapse (diagnosed with low-flow velocities on sonography) and high-grade stenosis cause similar infarction patterns with approximately half of patients having infarctions in watershed areas, though occlusions often have large territorial infarctions. ${ }^{20}$

- Some near-occlusions looked similar to conventional stenoses histologically, whereas some were actually recanalized thrombotic occlusions. ${ }^{21}$ However, the underlying study included both symptomatic and asymptomatic near-occlusions with a mean interval between the last symptom and surgery of 2.2 months. ${ }^{21}$

A theoretic model presented by Spencer and Reid ${ }^{22}$ noted that if a stenosis is sufficiently severe, incurring a large pressure drop, the flow from intracranial collaterals will create back pressure. With a sufficiently large pressure difference, the flow through the stenosis will decrease and the artery will collapse. Because stenoses can progress to near-occlusion, ${ }^{1}$ cases with near-occlusion have high back pressures ${ }^{9}$ and visible collaterals. ${ }^{13,14}$ When flow is poised to reduce, the flow velocities are still high, as seen in cases without full collapse having high flow velocities. ${ }^{3,10}$ This model seems robust in vivo and may explain varying sonographic findings in near-occlusion.

Usable circle of Willis and/or external carotid collaterals should exist for developing near-occlusion, though some individuals may not have usable collaterals. ${ }^{23}$ It may be that without intracranial collaterals, near-occlusion may not develop when stenosis progresses; rather, hemodynamic strokes may occur instead. No report examined this possibility, to our knowledge.

The diagnosis of near-occlusion is more difficult in cases with contralateral disease. ${ }^{2,24}$ However, the impact of contralateral disease on collateral use and prognosis has not been studied.

True hypoplasia is rare, between $0.01 \%$ and $0.24 \% .{ }^{25-27}$ Most cases of near-occlusion show true artery collapse with a reduced outer diameter, and it inflates after the stenosis is removed. ${ }^{9}$ However, on CTA, the cross-section of the carotid canal can look like "an island in a lake" or a "small brook in a large river bed" in cases of near-occlusion with full collapse (Fig 1). In contrast, true ICA hypoplasia is seen as a thin artery with a thin bony canal on CTA (Fig 1), without prominent ICA bulb stenosis.

Mechanism behind Recurrent Strokes. Near-occlusion with full collapse might cause a high risk of recurrent stroke. ${ }^{1,3,7}$ If confirmed, by what mechanism can near-occlusion with full collapse cause the observed higher stroke risk? It has been reported that untreated near-occlusions often progress to occlusion. ${ }^{7}$ However, a recent article found that none of 4 fully collapsed near-occlusions progressed to occlusion when examined after presumed embolic recurrent stroke. ${ }^{3}$ Other pathophysiologic mechanisms of near-occlusion with and without full collapse have not been studied. Both hemodynamic and embolic mechanisms are reasonable for the possible high risk of stroke among patients with symptomatic near-occlusion with full collapse.

As near-occlusion progresses from without-to-full collapse, the ipsilateral hemisphere receives less from its carotid artery and more from collaterals. Patients with near-occlusion with full collapse show compromised cerebral hemodynamics ${ }^{15}$; it is reasonable to suspect a hemodynamic mechanism for recurrent strokes. The presence or absence of systemic hypotension at the time of recurrence was not analyzed in previous studies. ${ }^{1,3,7}$

Severe flow reduction of near-occlusion with full collapse stimulates blood stagnation with presumed increased risk of 


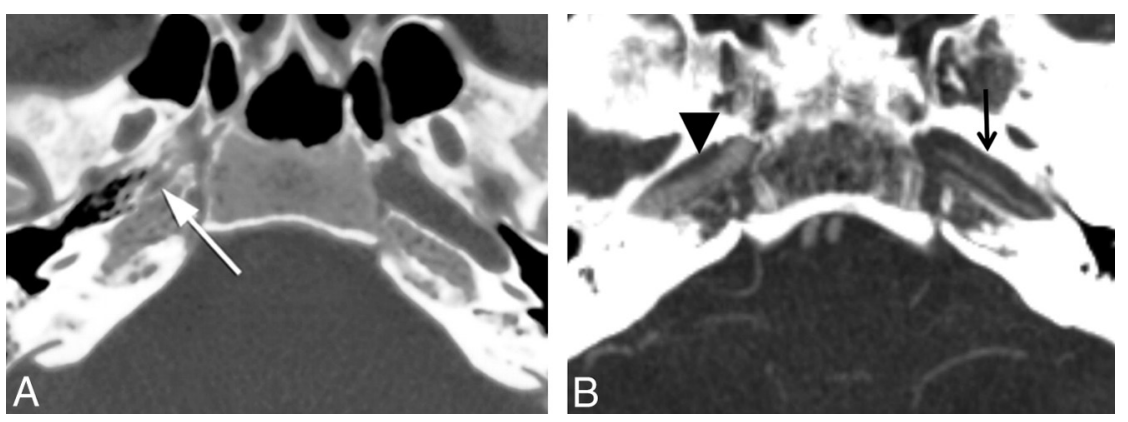

FIG 1. Comparison of bony carotid canals with ICA hypoplasia and near-occlusion. A, A case of right ICA hypoplasia. A narrow bony carotid canal (white arrow) - smaller than that on the contralateral side. Reprinted with permission from Ibrahim et al. ${ }^{58} \mathrm{~B}$, A case of left near-occlusion with full collapse. The narrow left ICA (black arrow) is in a normal-sized bone channel- "a small brook in a large river bed." Bone channels are similar on the left (black arrow) and right (black arrowhead).

thrombus formation, leading to embolic risk from the ICA bifurcation up to the first good intracranial collateral. Comparably, ischemic events from embolic mechanisms were seen for $3 \%$ of cases undergoing balloon occlusion for unclippable aneurysms. ${ }^{28}$ Such embolic risk seems greatest before thrombus organization, likely a short-lived phenomenon. Most stroke recurrences occurred early (within 1 month), ${ }^{1,3,7}$ indicating a short-lived strokerisk increase followed by stability, supporting the embolic mechanism. Even though reduced flow may lower embolic transportation in near-occlusion, full-collapse cases might still be at increased risk of embolic strokes overall from increased thrombus formation. Indeed, some near-occlusions are likely recanalized thrombotic occlusions. ${ }^{21}$

\section{Confusion about Near-Occlusion}

In Part 1 of this review, we presented the terminology, definition, and diagnosis of near-occlusion. ${ }^{2}$ Because some of the confusion in terminology definition and diagnosis is interwoven with prognosis, treatment, and pathophysiology, all issues are presented here.

Terminology and Definition. The multitude of terms for nearocclusion and their interchangeable use may contribute to confusion. The expanded near-occlusion definition, including subtle collapse in NASCET, ${ }^{14}$ was not recognized by all. "Near-occlusion" was used interchangeably with the "string sign" (or similar variations), even though the "string sign" (full collapse) is a subset of near-occlusion.

Near-occlusion without full collapse continues to be ignored, unknown by many. Existing guidelines do not clearly acknowledge this diagnosis. ${ }^{29,30}$ Educational articles, ${ }^{31,32}$ reviews, ${ }^{33}$ editorials, ${ }^{34,35}$ and book chapters ${ }^{36}$ do not acknowledge this diagnosis (with few exceptions). ${ }^{37,38}$ Without recognition, incorrect calculations for NASCET percentage stenosis are performed for near-occlusion without full collapse. In addition, near-occlusion without full collapse is the natural intermediate step between severe stenosis with normal-caliber ICA beyond it and near-occlusion with full collapse. Yet near-occlusion without full collapse is well documented-but ignored. Many authors ${ }^{10,16,34,39-43}$ have cited outcomes of near-occlusions with full collapse from the 1997 NASCET article ${ }^{14}$ as the outcome of all near-occlusions, without mention or explanation of those without full collapse. In contrast, fewer correctly made this distinction when citing that article. ${ }^{17,18}$

In some articles, terms for nearocclusion ("pseudo-occlusion" and "string sign") were used differently from those for severe atherosclerotic stenosis, and clearly for another entity. ${ }^{44-53}$ However, in other articles, terms for near-occlusion have been used inappropriately by also including carotid stenoses without distal collapse in the term but without clarification that something else was intended; rather the findings were directly compared with those in nearocclusion studies, ${ }^{42,54}$ or the article was educational without references. ${ }^{31}$ Specifically, with high-flow velocities on sonography, many high-grade conventional stenoses can be called "near-total occlusion." ${ }^{42}$ In 2 articles, threadlike stenosis without distal collapse was called the "string sign." 54,31

Diagnosis. Near-occlusion should be listed as "near-occlusion," not as a "percentage stenosis." Suggestions that the contralateral ICA be used as a denominator when the ipsilateral ICA is collapsed, creating tight percentage stenosis, ${ }^{55}$ seem an extraordinary devotion to percentage stenosis without recognizing the reality of near-occlusion. The prognosis of part-near-occlusion seems to differ from that in severe stenosis ${ }^{1}$; using the contralateral ICA as a denominator for percentage seems inappropriate. Some argued that the NASCET method is fallacious because the distal artery can collapse, ${ }^{56}$ though this argument ignores the fact that NASCET called for recognition of near-occlusions and requested that such stenoses not be graded with percentages. ${ }^{37}$ Those who do otherwise are not performing the NASCET grading as recommended. It is important to exclude distal artery collapse before grading a carotid stenosis; subtle collapses can be overlooked and not identified as near-occlusion if not actively sought consistently. If you do not seek it, you will not find it.

Prognosis and Treatment. Smaller studies, ${ }^{6,7}$ before NASCET and ECST, suggested that near-occlusions with full collapse have a high risk of stroke; this suggestion was negated by NASCET and ECST. ${ }^{1}$ However, NASCET and ECST mostly included near-occlusion without full collapse. Recently suggested are relevant differences of short-term prognosis between symptomatic near-occlusion with and without full collapse, ${ }^{3}$ differing from previous knowledge, ${ }^{1}$ with symptomatic near-occlusion without full collapse associated with a lower risk of recurrent stroke. However, symptomatic nearocclusion with full collapse is rarely studied, with conflicting results; it could have a high risk of recurrent stroke, ${ }^{1,3,6,7}$ which was not picked up by NASCET and ECST. After all, those studies were both randomized trials requiring patients to be acceptable candidates for both medical and surgical treatment arms, the equipoise requirement for a randomized treatment trial. In the late 1980s and early 1990s, few cases with fully collapsed ICA beyond a bulb stenosis would have been randomized. 


\section{Need for Future Improvement}

Near-occlusion without full collapse needs recognition for future studies, guidelines, and clinical practice. Many seem unaware of this diagnostic category. As a result, patients can presumably be misdiagnosed as having conventional carotid stenosis, even nonsignificant stenosis, severely affecting management. Current guidelines simply state that near-occlusion has a low risk of stroke. ${ }^{29,30}$ Awareness of near-occlusion with only full collapse will not pick up partial near-occlusion. Guidelines should be revised to highlight the 2 types of near-occlusion, that near-occlusion without full collapse has been well-studied but misunderstood by many, and that only this type may have a lower risk of stroke. On the other hand, near-occlusion with full collapse is widely known, but its real stroke risk is less known.

Further studies of symptomatic near-occlusion prognosis with full collapse are warranted. Some small studies suggest a high risk of recurrent stroke, ${ }^{3,7}$ despite being thought of as low. ${ }^{1}$ If this high risk is further documented, a randomized trial is warranted.

\section{Several Other Areas for Improvement.}

- More high-quality studies comparing sonography, CTA, and MR imaging with conventional angiography are warranted.

- Sonography, common as the first and often only carotid imaging, cannot distinguish near-occlusion without full collapse from conventional stenosis with peak systolic velocity analyzed. Other velocity or diameter measurements or both need analysis.

- A small sonographic study reported how often different pathologic flow profiles indicate distal occlusion or near-occlusion in situ. ${ }^{57}$ This should be reproduced.

- The value of contrast-enhanced sonography to better distinguish near-occlusion from occlusion should be evaluated.

- The prognosis of asymptomatic near-occlusion is unknown.

- It is not well worked out if the mechanism for recurrent strokes in patients with near-occlusion with and without full collapse is predominantly hemodynamic or predominantly embolic.

Disclosures: Elias Johansson—RELATED: Grant: Several smaller stroke funds contributed, with funding listed in the footnotes*; none had any influence on the content. Conforms to "no disclosures." Allan J. Fox_UNRELATED: Expert Testimony: medical malpractice suits, none relevant to the topic of this work. *Money paid to the institution.

\section{REFERENCES}

1. Fox AJ, Eliasziw M, Rothwell PM, et al. Identification, prognosis, and management of patients with carotid artery near occlusion. AJNR Am J Neuroradiol 2005;26:2086-94 Medline

2. Johansson E, Fox AJ. Carotid near-occlusion: a comprehensive review, part 1-definition, terminology and diagnosis carotid nearocclusion. AJNR Am J Neuroradiol 2016;37:2-10 CrossRef Medline

3. Johansson E, Öhman K, Wester P. Symptomatic carotid near-occlusion with full collapse might cause a very high risk of stroke. J Intern Med 2015;277:615-23 CrossRef Medline

4. Rothwell PM, Eliasziw M, Gutnikov SA, et al; Carotid Endarterectomy Trialists' Collaboration. Analysis of pooled data from the randomised controlled trials of endarterectomy for symptomatic carotid stenosis. Lancet 2003;361:107-16 CrossRef Medline

5. Koutsoumpelis A, Kouvelos G, Peroulis M, et al. Surgical and endovascular intervention on internal carotid artery near occlusion. Int Angiol 2015;34:172-81 Medline

6. Ringelstein EB, Berg-Dammer E, Zeumer H. The so-called athero- matous pseudoocclusion of internal carotid artery: a diagnostic and therapeutical challenge. Neuroradiology 1983;25:147-55 CrossRef Medline

7. O'Leary DH, Mattle H, Potter JE. Atheromatous pseudo-occlusion of the internal carotid artery. Stroke 1989;20:1168-73 CrossRef Medline

8. Halliday A, Mansfield A, Marro J, et al; MRC Asymptomatic Carotid Surgery Trial (ACST) Collaborative Group. Prevention of disabling and fatal strokes by successful carotid endarterectomy in patients without recent neurological symptoms: randomised controlled trial. Lancet 2004;363:1491-502 CrossRef Medline

9. Archie JP. Carotid endarterectomy when the distal internal carotid artery is small or poorly visualized. J Vasc Surg 1994;19:23-30; discussion 30-31 CrossRef Medline

10. El-Saden SM, Grant EG, Hathout GM, et al. Imaging of the internal carotid artery: the dilemma of total versus near total occlusion. $R a$ diology 2001;221:301-08 CrossRef Medline

11. Mansour MA, Mattos MA, Hood DB, et al. Detection of total occlusion, string sign, and preocclusive stenosis of the internal carotid artery by color-flow duplex scanning. Am J Surg 1995;170:154-58 CrossRef Medline

12. Hetzel A, Eckenweber B, Trummer B, et al. Colour-coded duplex sonography of preocclusive carotid stenoses. Eur J Ultrasound 1998; 8:183-91 CrossRef Medline

13. Henderson R, Eliasziw M, Fox AJ, et al; North American Symptomatic Carotid Endarterectomy Trial (NASCET) Group. Angiographically defined collateral circulation and risk of stroke in patients with severe carotid artery stenosis. Stroke 2000;31:128-32 CrossRef Medline

14. Morgenstern LB, Fox AJ, Sharpe BL, et al; North American Symptomatic Carotid Endarterectomy Trial (NASCET) Group. The risks and benefits of carotid endarterectomy in patients with near occlusion of the carotid artery. Neurology 1997;48:911-15 CrossRef Medline

15. Oka F, Ishihara H, Kato S, et al. Cerebral hemodynamic benefits after carotid artery stenting in patients with near occlusion. $J$ Vasc Surg 2013;58:1512-17 CrossRef Medline

16. Terada T, Tsuura M, Matsumoto H, et al. Endovascular treatment for pseudo-occlusion of the internal carotid artery. Neurosurgery 2006;59:301-09; discussion 301-09 CrossRef Medline

17. González A, Gil-Peralta A, Mayol A, et al. Internal carotid artery stenting in patients with near occlusion: 30-day and long-term outcome. AJNR Am J Neuroradiol 2011;32:252-58 CrossRef Medline

18. Choi BS, Park JW, Shin JE, et al. Outcome evaluation of carotid stenting in high-risk patients with symptomatic carotid near occlusion. Interv Neuroradiol 2010;16:309-16 Medline

19. Greiner C, Wassmann H, Palkovic S, et al. Revascularization procedures in internal carotid artery pseudo-occlusion. Acta Neurochir (Wien) 2004;146:237-43; discussion 243 CrossRef Medline

20. Szabo K, Kern R, Gass A, et al. Acute stroke patterns in patients with internal carotid artery disease: a diffusion-weighted magnetic resonance imaging study. Stroke 2001;32:1323-29 CrossRef Medline

21. Hirata Y, Sakata N, Inoue T, et al. Histopathological features with angiographic correlates of internal carotid artery pseudoocclusion: impact of plaque compositions - clinical article. J Neurosurg 2011;115:350-58 CrossRef Medline

22. Spencer MP, Reid JM. Quantitation of carotid stenosis with continuous-wave (C-W) Doppler ultrasound. Stroke 1979;10:326-30 CrossRef Medline

23. Hoksbergen AW, Legemate DA, Ubbink DT, et al. Collateral variations in circle of Willis in atherosclerotic population assessed by means of transcranial color-coded duplex ultrasonography. Stroke 2000;31:1656-60 CrossRef Medline

24. Bartlett ES, Walters TD, Symons SP, et al. Diagnosing carotid stenosis near-occlusion by using CT angiography. AJNR Am J Neuroradiol 2006;27:632-37 Medline

25. Chen CJ, Lee TH, Hsu HL, et al. Multi-slice CT angiography in diagnosing total versus near occlusions of the internal carotid artery: 
comparison with catheter angiography. Stroke 2004;35:83-85 Medline

26. Okahara M, Kiyosue $\mathrm{H}$, Mori $\mathrm{H}$, et al. Anatomic variations of the cerebral arteries and their embryology: a pictorial review. Eur Radiol 2002;12:2548-61 CrossRef Medline

27. Ito $\mathrm{S}$, Miyazaki $\mathrm{H}$, Iino $\mathrm{N}$, et al. Unilateral agenesis and hypoplasia of the internal carotid artery: a report of three cases. Neuroradiology 2005;47:311-15 CrossRef Medline

28. Fox AJ, Viñuela F, Pelz DM, et al. Use of detachable balloons for proximal artery occlusion in the treatment of unclippable cerebral aneurysms. J Neurosurg 1987;66:40-46 CrossRef Medline

29. European Stroke Organisation (ESO) Executive Committee, ESO Writing Committee. Guidelines for management of ischaemic stroke and transient ischaemic attack 2008. Cerebrovasc Dis 2008;25: 457-507 CrossRef Medline

30. Furie KL, Kasner SE, Adams RJ, et al; American Heart Association Stroke Council, Council on Cardiovascular Nursing, Council on Clinical Cardiology, and Interdisciplinary Council on Quality of Care and Outcomes Research. Guidelines for the prevention of stroke in patients with stroke or transient ischemic attack: a guideline for healthcare professionals from the American Heart Association/ American Stroke Association. Stroke 2011;42:227-76 CrossRef Medline

31. Gross K, Wang H. The string sign. J Vasc Nurs 2000;18:72 CrossRef Medline

32. Pappas JN. The angiographic string sign. Radiology 2002;222:237-38 CrossRef Medline

33. Giannoukas AD, Labropoulos N, Smith FC, et al. Management of the near total internal carotid artery occlusion. Eur J Vasc Endovasc Surg 2005;29:250-55 CrossRef Medline

34. Yadav JS. Functional occlusions of the carotid artery (string signs): to treat or not to treat? JACC Cardiovasc Interv 2010;3:305-06 CrossRef Medline

35. Bazan HA. Carotid string sign is not necessarily a functional occlusion: admit, anticoagulate, and revascularize urgently. Catheter Cardiovasc Interv 2010;75:1110 CrossRef Medline

36. Biller J, Love BB, Schneck MJ. Vascular diseases of the nervous system: ischemic cerebrovascular disease. In: Daroff RB, Fenichel GM, Jankovic J, et al, eds. Bradley's Neurology in Clinical Practice. 6th ed. Philadelphia: Elsevier; 2012:1046

37. Fox AJ. How to measure carotid stenosis. Radiology 1993;186: 316-18 CrossRef Medline

38. Fox AJ, Symons SP, Aviv RI, et al. Falsely claiming use of NASCET percentage stenosis method. Radiology 2009;253:574-75; author reply 575 CrossRef Medline

39. Son S, Choi DS, Kim SK, et al. Carotid artery stenting in patients with near occlusion: a single-center experience and comparison with recent studies. Clin Neurol Neurosurg 2013;115:1976-81 CrossRef Medline

40. Sakamoto S, Kiura Y, Kajihara Y, et al. Carotid artery stenting using the proximal or dual protection method for near occlusion of the cervical internal carotid artery. Neurosurg Rev 2013;36:551-57; discussion 557-58 CrossRef Medline

41. Nikas DN, Ghany MA, Stabile E, et al. Carotid artery stenting with proximal cerebral protection for patients with angiographic ap- pearance of string sign. JACC Cardiovasc Interv 2010;3:298-304 CrossRef Medline

42. Radak DJ, Tanaskovic S, Ilijevski NS, et al. Eversion carotid endarterectomy versus best medical treatment in symptomatic patients with near total internal carotid occlusion: a prospective nonrandomized trial. Ann Vasc Surg 2010;24:185-89 CrossRef Medline

43. Ferguson GG. Comment on "Revascularization procedures in ICA pseudo-occlusion.” Acta Neurochir (Wien) 2004;146:243

44. Kniemeyer HW, Aulich A, Schlachetzki F, et al. Pseudo- and segmental occlusion of the internal carotid artery: a new classification, surgical treatment and results. Eur J Vasc Endovasc Surg 1996;12:310-20 CrossRef Medline

45. Ascher E, Markevich N, Hingorani A, et al. Pseudo-occlusions of the internal carotid artery: a rationale for treatment on the basis of a modified duplex scan protocol. J Vasc Surg 2002;35:340-45 CrossRef Medline

46. Macpherson P. Pseudo-occlusion of the internal carotid artery. $\mathrm{Br}$ Radiol 1978;51:5-10 CrossRef Medline

47. Regina G, Testini M, Fullone M, et al. Pseudo-occlusion of the inter nal carotid artery: report of 15 cases and review of the literature. Int Angiol 1997;16:147-50 Medline

48. Sitzer M, Fürst G, Fischer H, et al. Between-method correlation in quantifying internal carotid stenosis. Stroke 1993;24:1513-18 CrossRef Medline

49. Ammar AD, Turrentine MW, Farha SJ. The importance of arteriographic interpretation in occlusion or pseudo-occlusion of the carotid artery. Surg Gyn Obst 1988;167:119-23 Medline

50. Mehigan JT, Olcott C 4th. The carotid "string" sign: differential diagnosis and management. Am J Surg 1980;140:137-43 CrossRef Medline

51. Marquering HA, Nederkoorn PJ, Beenen LF, et al. Carotid pseudoocclusion on CTA in patients with acute ischemic stroke: a concerning observation. Clin Neurol Neurosurg 2013;115:1591-94 CrossRef Medline

52. Ojemann RG, Fisher CM, Rich JC. Spontaneous dissecting aneurysm of the internal carotid artery. Stroke 1972;3:434-40 CrossRef Medline

53. Ehrenfeld WK, Wylie EJ. Spontaneous dissection of the internal carotid artery. Arch Surg 1976;111:1294-1301 CrossRef Medline

54. Berman SS, Devine JJ, Erdoes LS, et al. Distinguishing carotid artery pseudo-occlusion with color-flow Doppler. Stroke 1995;26:434-38 CrossRef Medline

55. Dix JE, McNulty BJ, Kallmes DF. Frequency and significance of a small distal ICA in carotid artery stenosis. AJNR Am J Neuroradiol 1998;19:1215-18 Medline

56. Ruiz-Salmerón RJ, Gamero MA, Carrascosa C, et al. Carotid artery stenting: clinical and procedural implications for near-occlusion stenosis. Neurologia 2013;28:535-42 CrossRef Medline

57. Fujimoto S, Toyoda K, Kishikawa K, et al. Accuracy of conventiona plus transoral carotid ultrasonography in distinguishing pseudoocclusion from total occlusion of the internal carotid artery. Cerebrovasc Dis 2006;22:170 -76 CrossRef Medline

58. Ibrahim M, Branson HM, Buncic JR, et al. A case of Horner syndrome with intermittent mydriasis in a patient with hypoplasia of the internal carotid artery. AJNR Am J Neuroradiol 2006;27:1318-20 Medline 